\title{
Solvent-Free Henry and Michael Reactions with Nitroalkanes Promoted by Potassium Carbonate as a Versatile Heterogeneous Catalyst
}

\author{
Giovanna Bosica $^{1}$ and Kurt Polidano ${ }^{2}$ \\ ${ }^{1}$ Department of Chemistry, University of Malta, Msida MSD 2080, Malta \\ ${ }^{2}$ Cardiff University, Main Building, Park Pl, Cardiff CF10 3AT, UK
}

Correspondence should be addressed to Giovanna Bosica; giovanna.bosica@um.edu.mt

Received 30 January 2017; Revised 13 April 2017; Accepted 21 May 2017; Published 15 June 2017

Academic Editor: Stojan Stavber

Copyright (C) 2017 Giovanna Bosica and Kurt Polidano. This is an open access article distributed under the Creative Commons Attribution License, which permits unrestricted use, distribution, and reproduction in any medium, provided the original work is properly cited.

\begin{abstract}
The use of a simple weak inorganic base such as potassium carbonate facilitated the formation of carbon-carbon bonds through both the Henry and the Michael reactions with nitrocompounds. The application of this catalyst under environmentally friendly solventless heterogeneous conditions gave satisfactory to good yields of $\beta$-nitroalcohols, involving aliphatic and aromatic starting materials, as well as high to excellent yields in the formation of Michael adducts using several different Michael acceptors and nitroalkanes.
\end{abstract}

\section{Introduction}

The formation of a carbon-carbon bond can be carried out using various starting materials together with a vast amount of homogeneous or heterogeneous catalysts. Two important reactions which involve the synthesis of compounds through carbon-carbon bond formation include the Henry and the Michael reactions with nitroalkanes [1-3]. Under basic conditions nitroalkanes are able to deprotonate to form an intermediate compound known as the nitronate anion [4]. The nitronate anion can then react with aldehydes through the Henry reaction to yield $\beta$-nitroalcohols [5]. In the case of the Michael addition, the carbanion would react with Michael acceptors or $\alpha, \beta$-unsaturated compounds to yield polyfunctionalised nitroderivatives [6].

In recent years the nitroaldol and the Michael reactions were carried out using extensive catalysts, some of which containing complex structures. Various methodologies have been employed; however, in some cases, disadvantages of having such complex structures included applying either very low or substantially high temperatures to obtain the respective products at great yields [7-10]. A major drawback of some catalysts is that they resulted in the increased formation of secondary products in these reactions. In the case of the nitroaldol reaction, the main side product is the formation of the nitroalkene through a further condensation reaction of the nitroalcohol. In some cases the use of certain catalysts resulted in the production of a conjugated enone through an aldol condensation side reaction, whereas some highly activated catalysts which were applied to the Michael addition were too reactive as reactions which resulted in the formation of the double addition products [4-6].

Herein, as a continuation of ongoing study on the development of environmentally friendly methodologies [1113], our main interest in relation to this context was to identify a simple alternative and cheap heterogeneous solid catalyst useful for both the Henry and the Michael reactions, in accordance with moderate reaction conditions and the concept of Green Chemistry [14] to produce, respectively, $\beta$ nitroalcohols (Scheme 1) and polyfunctionalised nitroderivatives (Schemes 2 and 3) [15-17]. On this purpose potassium carbonate $[18,19]$ was identified as a suitable catalyst and produced average to good results for the nitroaldol reaction (Table 3) and good to excellent results for the Michael addition (Table 4). To the best of our knowledge, potassium carbonate was previously reported to catalyse only a few 


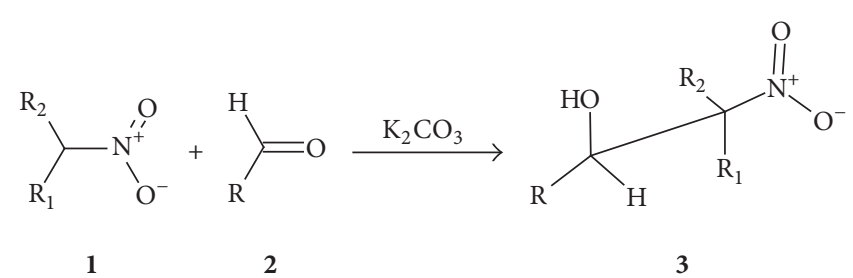

Scheme 1: The Henry (nitroaldol) reaction.

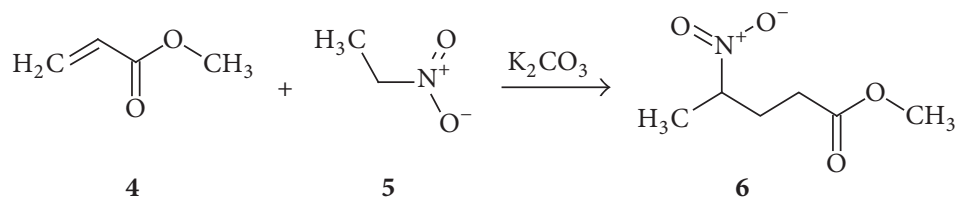

Scheme 2: Michael addition model reaction using methyl acrylate and nitroethane with $\mathrm{K}_{2} \mathrm{CO}_{3}$.

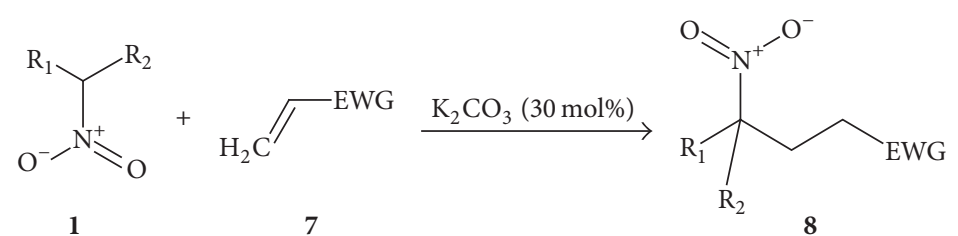

SCHEME 3: Michael reactions using $30 \mathrm{~mol} \% \mathrm{~K}_{2} \mathrm{CO}_{3}$.

examples of Michael addition reactions, although never under neat conditions but with the required assistance of solvents $[20,21]$, ultrasounds activation, and ionic liquids [22], or with the use of a limited number of substrates as starting materials [23] or else not involving nitroalkanes but different nucleophiles [24-26].

\section{Results and Discussion}

In both reactions, the first part of the study consisted of the optimization screening through the investigation of some Henry (Table 1) and Michael reactions (Table 2) using potassium carbonate as the catalyst together with the variation of both physical and chemical conditions and without any solvent.

The Michael reaction was first investigated by performing a variety of trials using nitroethane (5) and methyl acrylate (4) as model reaction (Scheme 2).

Following these preliminary investigations, the Henry reaction gave good results when undergone at temperatures of $60^{\circ} \mathrm{C}$, increasing the reaction rate substantially and using 10 molar\% of catalyst (entry 5, Table 1). On the other hand, high temperatures were detrimental to the Michael additions as a second by-product was afforded, this most probably being the double Michael adduct. In order to decrease the formation of the bis-addition, the reaction temperature was kept at room temperature to promote increased formation of the desired monoaddition and together with the use of 30 molar\% of catalyst the best result was obtained (entry 5, Table 2). These selected conditions were then employed in other Henry and Michael reactions in order to verify a more general applicability of the preliminary protocol, using nitroalkanes and different aldehydes and $\alpha, \beta$-unsaturated compounds, respectively.

As reported in Table 3, aliphatic aldehydes gave the best results in the least amount of reaction time while aromatic aldehydes with electron withdrawing substituents gave better yields than those containing electron donating groups. Parasubstituted aromatics were the most difficult substrates to react and when utilising 4-nitrobenzaldehyde a small amount of $\mathrm{CH}_{2} \mathrm{Cl}_{2}$ was required as the starting material was solid. In general average to good yields were obtained with this catalyst as the reaction itself is reversible [2] and thus it is difficult for it to reach completion. The major role played by the catalyst was that reactions only afforded in a selective way the nitroaldol product and no traces of any condensation side product were present.

The previous conditions were then applied to Michael reactions using different nitroalkanes and diversely functionalised Michael acceptors (Scheme 3) and the catalyst performed even better providing good to excellent product yields (Table 4). Only when using nitromethane were very low yields recorded, since the formation of the bis-addition side product was revealed due to the fact that it is a small and unhindered molecule, while using a secondary nitroalkane the temperature was increased to $60^{\circ} \mathrm{C}$ as there is no possible formation of the bis-adduct. Also the results obtained from these trials indicated that $30 \mathrm{~mol} \%$ of catalyst gave good yields at room temperature when using methyl acrylate as the Michael acceptor. However, reaction temperatures were increased to $60^{\circ} \mathrm{C}$ and $90^{\circ} \mathrm{C}$ when using cyclic and sterically hindered Michael acceptors like cyclic enones and trans-methyl crotonate in order to increase the speed of the reaction, whereas reactions which involved the use of 
TABLE 1: Optimization of nitroaldol reaction using $\mathrm{K}_{2} \mathrm{CO}_{3}$.

\begin{tabular}{|c|c|c|c|c|c|c|c|}
\hline Entry & $\mathrm{R}$ & $\mathrm{R}_{1}$ & $\mathrm{R}_{2}$ & $\begin{array}{l}\text { Mol (\%) } \\
\text { catalyst }\end{array}$ & $\begin{array}{c}\text { Temperature } \\
\left({ }^{\circ} \mathrm{C}\right) \\
\end{array}$ & Time (h) & $\begin{array}{c}\text { Yield }^{\mathrm{a}} \text { of } 3 \\
(\%)\end{array}$ \\
\hline 1 & $\mathrm{Ph}$ & $\mathrm{CH}_{3}$ & $\mathrm{H}$ & 10 & 25 & 24 & 35 \\
\hline 2 & $\mathrm{CH}_{3}$ & $\mathrm{CH}_{3}$ & $\mathrm{H}$ & 30 & 25 & 24 & 54 \\
\hline 3 & $\mathrm{CH}_{3}$ & $\mathrm{CH}_{3}$ & $\mathrm{H}$ & 10 & 60 & 4 & 48 \\
\hline 4 & $\mathrm{CH}_{3} \mathrm{CH}_{2} \mathrm{CH}_{2}$ & $\mathrm{CH}_{3}$ & $\mathrm{H}$ & 30 & 25 & 24 & 58 \\
\hline 5 & $\mathrm{CH}_{3} \mathrm{CH}_{2} \mathrm{CH}_{2}$ & $\mathrm{CH}_{3}$ & $\mathrm{H}$ & 10 & 60 & 4 & 68 \\
\hline
\end{tabular}

${ }^{\mathrm{a}}$ Yield of pure isolated products.

TABLE 2: Optimization of Michael reaction using model reaction.

\begin{tabular}{lcccc}
\hline Entry & $\begin{array}{c}\text { Mol \% } \\
\text { catalyst }\end{array}$ & $\begin{array}{c}\text { Time } \\
(\mathrm{h})\end{array}$ & $\begin{array}{c}\text { Temperature } \\
\left({ }^{\circ} \mathrm{C}\right)\end{array}$ & $\begin{array}{c}\text { Yield } \text { of }^{\mathbf{6}} \\
(\%)\end{array}$ \\
\hline $\mathbf{1}$ & 10 & 5 & 25 & 47 \\
$\mathbf{2}$ & 10 & $27^{\mathrm{b}}$ & $25,60^{\mathrm{b}}$ & 50 \\
$\mathbf{3}$ & 20 & 24 & 25 & 58 \\
$\mathbf{4}$ & 10 & 7 & 60 & 60 \\
$\mathbf{5}$ & 30 & 7.5 & 25 & 61 \\
$\mathbf{6}$ & 30 & 48 & 25 & 58 \\
$\mathbf{7}$ & 30 & 6 & 50 & 58 \\
$\mathbf{8}$ & 30 & 7 & 35 & 55 \\
\hline
\end{tabular}

${ }^{a}$ Yield of pure isolated product.

${ }^{\mathrm{b}}$ Reaction was carried out at room temperature for 24 hours; temperature was increased to $60^{\circ} \mathrm{C}$ for 3 hours.

TABLE 3: Henry reaction using $10 \mathrm{~mol} \% \mathrm{~K}_{2} \mathrm{CO}_{3}$ at $60^{\circ} \mathrm{C}$.

\begin{tabular}{lccccc}
\hline Entry & $\mathrm{R}$ & $\mathrm{R}_{1}$ & $\mathrm{R}_{2}$ & Time $(\mathrm{h})$ & Yield $^{\mathrm{a}}$ of $3(\%)$ \\
\hline $\mathbf{a}$ & $\mathrm{CH}_{3}$ & $\mathrm{CH}_{3}$ & $\mathrm{H}$ & 4 & 48 \\
$\mathbf{b}$ & $\mathrm{CH}_{3} \mathrm{CH}_{2} \mathrm{CH}_{2}$ & $\mathrm{CH}_{3}$ & $\mathrm{CH}_{3}$ & 5 & 46 \\
$\mathbf{c}$ & $\mathrm{CH}_{3}$ & $\mathrm{H}$ & $\mathrm{H}$ & 4.5 & 75 \\
$\mathbf{d}$ & $\mathrm{Ph}$ & $\mathrm{CH}_{3}$ & $\mathrm{H}$ & 4.5 & 40 \\
$\mathbf{e}$ & $\mathrm{CH}_{3}$ & $\mathrm{CH}_{3}$ & $\mathrm{CH}_{3}$ & 4 & 50 \\
$\mathbf{f}$ & $\mathrm{PhCH}_{2}$ & $n-\mathrm{C}_{2} \mathrm{H}_{5}$ & $\mathrm{H}$ & 5 & 60 \\
$\mathbf{g}$ & $\mathrm{CH}_{3} \mathrm{CH}_{2} \mathrm{CH}_{2} \mathrm{CH}_{2}$ & $n-\mathrm{C}_{2} \mathrm{H}_{5}$ & $\mathrm{H}$ & 4.5 & 58 \\
$\mathbf{h}$ & $\mathrm{PhCH}_{2} \mathrm{CH}_{2}$ & $n-\mathrm{C}_{3} \mathrm{H}_{7}$ & $\mathrm{H}$ & 6.5 & 72 \\
$\mathbf{i}$ & $n-\mathrm{C}_{5} \mathrm{H}_{11}$ & $n-\mathrm{C}_{3} \mathrm{H}_{7}$ & $\mathrm{H}$ & 8 & $55^{\mathrm{b}}$ \\
$\mathbf{j}$ & $p-\mathrm{NO}_{2} \mathrm{C}_{6} \mathrm{H}_{4}$ & $n-\mathrm{C}_{4} \mathrm{H}_{9}$ & $\mathrm{H}$ & 72 & 60 \\
$\mathbf{k}$ & $\mathrm{Ph}$ & $\mathrm{H}$ & $\mathrm{H}$ & 3.5 & 65 \\
$\mathbf{1}$ & $c-\mathrm{C}_{6} \mathrm{H}_{11}$ & $\mathrm{H}$ & $\mathrm{H}$ & 5 & 60 \\
$\mathbf{m}$ & $p-\mathrm{OCH}_{3} \mathrm{C}_{6} \mathrm{H}_{4}$ & $\mathrm{H}$ & $\mathrm{H}$ & 24 & $66^{\mathrm{b}}$ \\
$\mathbf{n}$ & $p-\mathrm{NO}_{2} \mathrm{C}_{6} \mathrm{H}_{4}$ & $\mathrm{H}$ & $\mathrm{H}$ & 4 & 62 \\
$\mathbf{o}$ & $\mathrm{CH}_{3}$ & $\mathrm{Br}$ & $\mathrm{H}$ & 5 & \\
\hline
\end{tabular}

${ }^{\mathrm{a}}$ Yield of pure isolated product.

${ }^{\mathrm{b}}$ Reaction was carried out under $\mathrm{CH}_{2} \mathrm{Cl}_{2}$ solvent as the starting aldehyde was solid.

acrylonitrile required lower temperatures of $0^{\circ} \mathrm{C}$ to prevent immediate polymerization of acrylonitrile from occurring, which was evident through the formation of a thick yellow solid.

\section{Conclusions}

In summary, the utilisation of potassium carbonate in neat conditions is a very versatile and green synthetic method and thus shows great applicability with a variety of substrates, containing different backbone structures, such as aliphatic straight chain and cyclic and aromatic compounds, to undergo both Henry and Michael reactions. Compared with the reported methods using expensive or unavailable organic catalysts, a common and inexpensive inorganic base $\left(\mathrm{K}_{2} \mathrm{CO}_{3}\right)$ was here employed as the base catalyst. The presented reactions proceeded with complete regioselectivity providing the nitroaldol and Michael monoaddition products, respectively, 


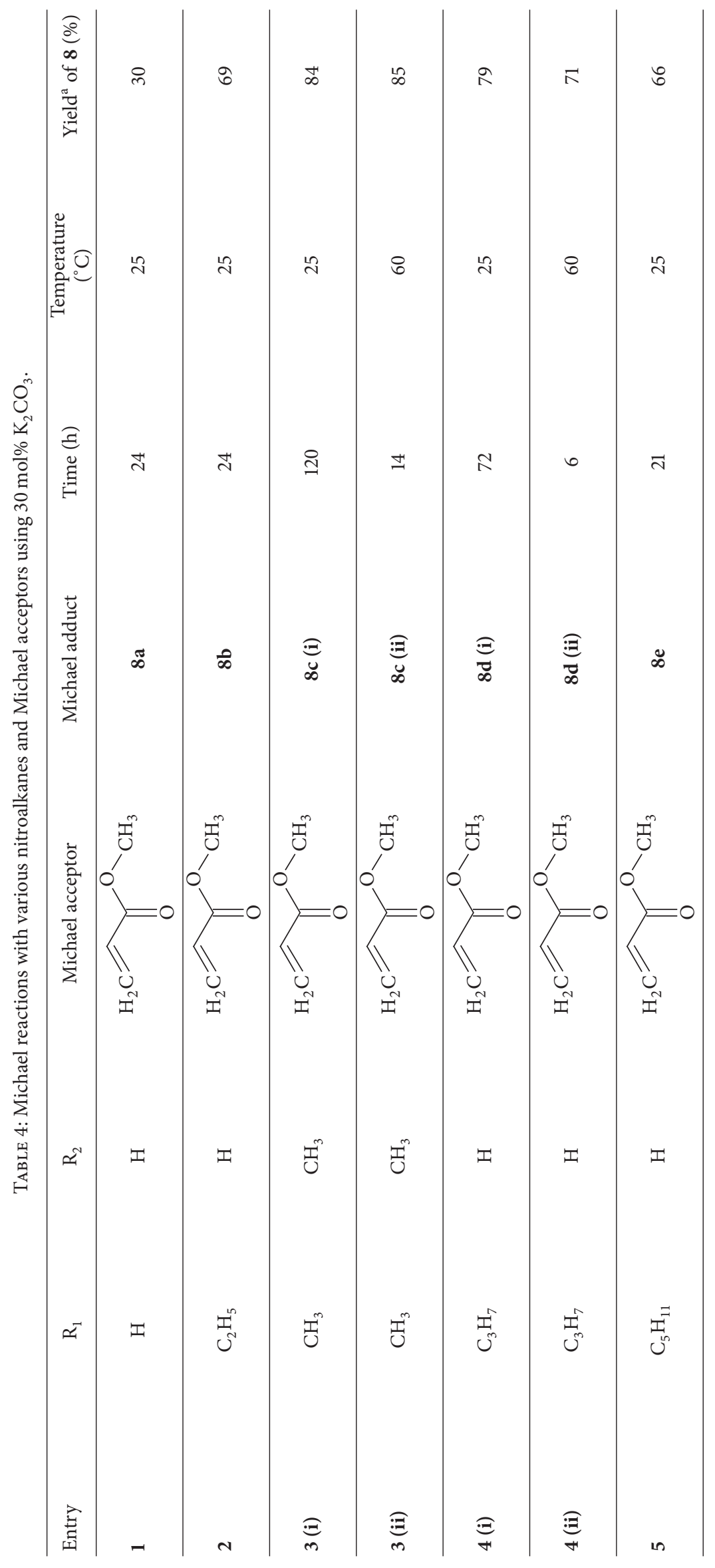




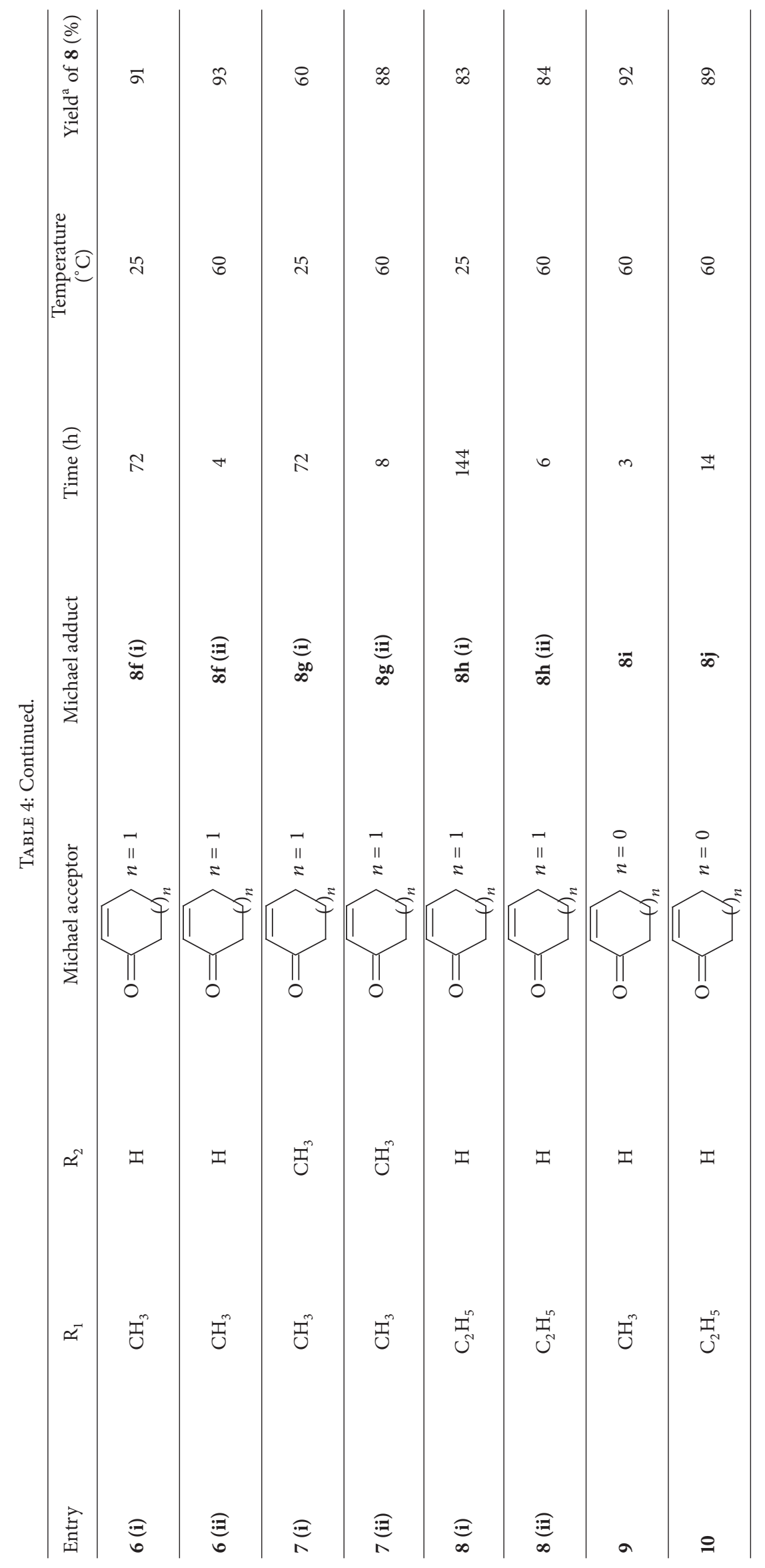




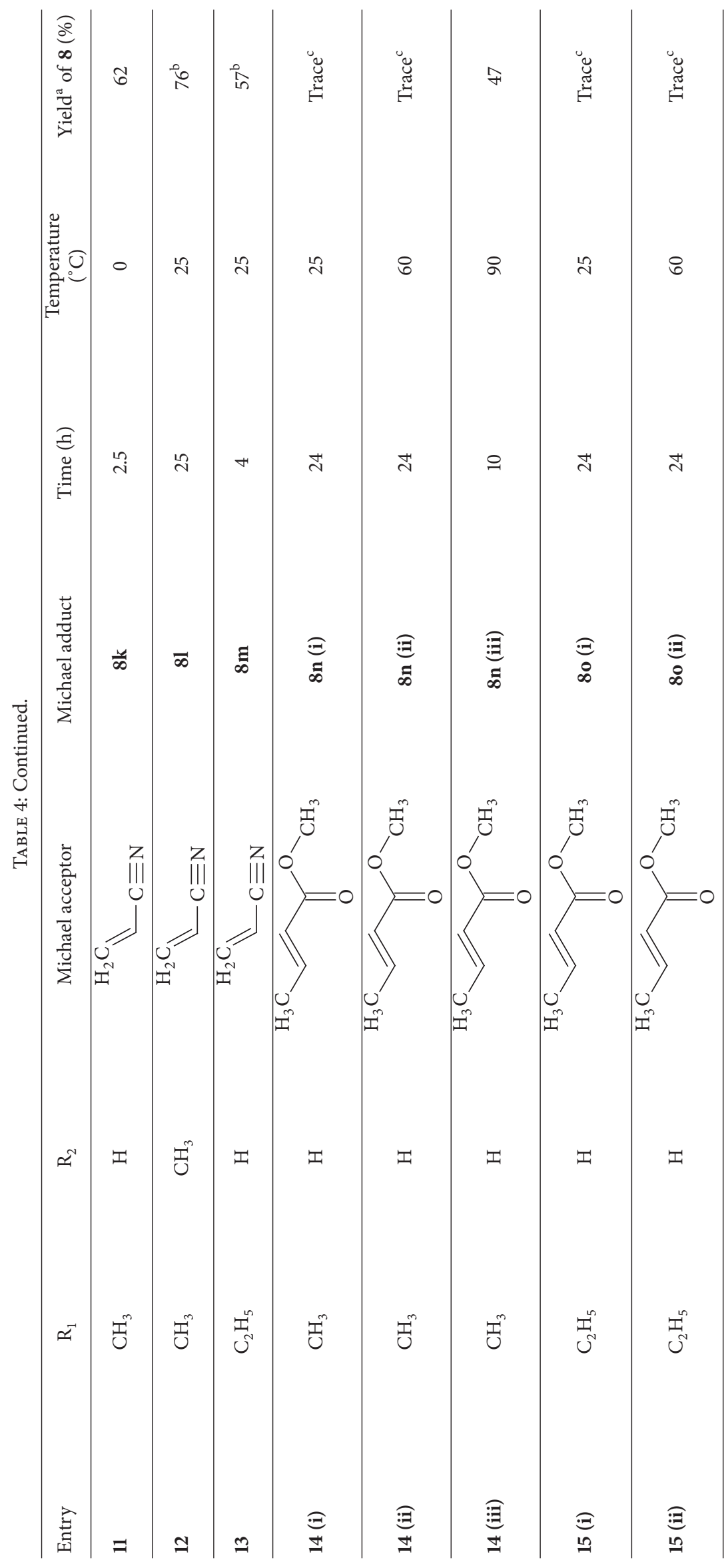




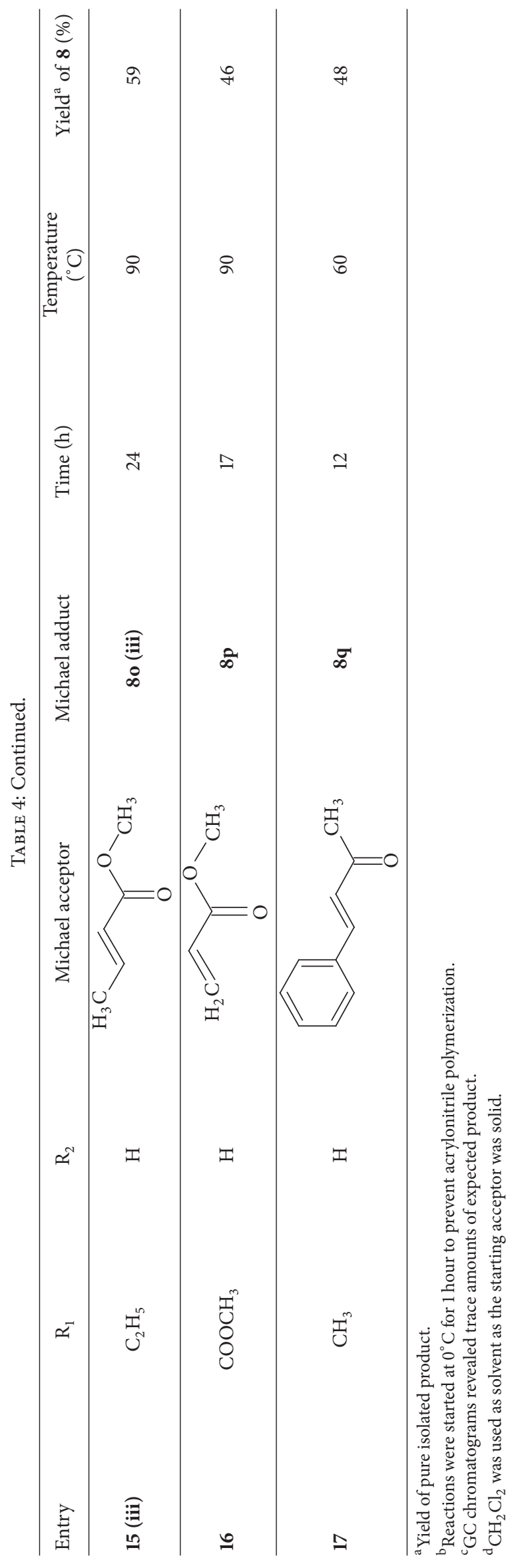


while tolerating many different functionalities. The common catalyst and the ready availability of the starting materials and the simplicity and versatility of the procedure and the valuable products make the protocol potentially practical and useful to synthetic chemists.

\section{Experimental Section}

4.1. General Information. All commercially available chemicals and reagents were purchased from Aldrich and used without further purification. IR spectra were recorded on a Shimadzu IRAffinity-1 FTIR Spectrometer, calibrated against a $1602 \mathrm{~cm}^{-1}$ polystyrene absorbance spectrum. Samples were either analysed as a thin film or in a $\mathrm{Nujol}^{\mathrm{TM}}$ mull, between sodium chloride discs. The ${ }^{1} \mathrm{H}$ - and ${ }^{13} \mathrm{C}$-NMR spectra were recorded on Bruker AM250 NMR spectrometer fitted with a dual probe at frequencies of $250 \mathrm{MHz}$ and $62.9 \mathrm{MHz}$ for ${ }^{1} \mathrm{H}$ and ${ }^{13} \mathrm{C}$ NMR, respectively. An Aspect 3000 computer using $16 \mathrm{~K}$ complex points for ${ }^{1} \mathrm{H}$ NMR and $64 \mathrm{~K}$ complex points for ${ }^{13} \mathrm{C}$ NMR was used for processing. Samples were dissolved in deuterated chloroform (with TMS): $5 \mathrm{mg}$ in $0.8 \mathrm{~mL} \mathrm{CDCl}_{3}$ for ${ }^{1} \mathrm{H}$ NMR and between $35 \mathrm{mg}$ and $50 \mathrm{mg}$ in $0.8 \mathrm{~mL}$ $\mathrm{CDCl}_{3}$ for ${ }^{13} \mathrm{C} \mathrm{NMR}$. Reaction monitoring was done by TLC and GC analysis. Ready-purchased silica on PET sheets with fluorescent indicator, $254 \mathrm{~nm}$, was used as stationary phase for TLC. Gas chromatography was carried out on a Shimadzu GC-2010 plus gas chromatograph equipped with a flame ionisation detector and HiCap 5 GC column with dimensions of $0.32 \mathrm{~mm}$ (internal diameter) $\times 30 \mathrm{~m}$ (length) $\times 0.25 \mu \mathrm{m}$ (film thickness), using nitrogen as carrier gas. The synthesised compounds are known. Supplemental material (available online at https://doi.org/10.1155/2017/6267036) is available from the correspondence author.

\subsection{Typical Procedure for the Nitroaldol Reaction and the} Formation of 3-Nitro-2-butanol (3a). The nitroalkane, nitroethane $(20 \mathrm{mmol})$, and the aldehyde, acetaldehyde (20 mmol), were mixed together. After thorough mixing, potassium carbonate $(10 \mathrm{~mol} \%)$ was added to the mixture. The reaction temperature was increased and monitored until it reached $60^{\circ} \mathrm{C}$. Immediately after the reaction finished as observed from TLC, the catalyst was filtered off using a Grade 1 filter paper and dichloromethane as solvent. The solvent was evaporated and the crude product was purified by column chromatography using a mixture of cyclohexane and ethyl acetate giving (48\%) of $3 \mathbf{a}$ as $6: 4$ diastereomeric mixture: IR (neat): $\nu_{\max } 3421,2985,2943,2910$, and 1548, $\mathrm{cm}^{-1}$ and ${ }^{1} \mathrm{H}$ NMR $\left(250 \mathrm{MHz}, \mathrm{CDCl}_{3}\right) \delta 1.24-1.3(\mathrm{dd}, J=$ $9.66 \mathrm{~Hz}, 3 \mathrm{H}), \delta 1.54-1.59(\mathrm{dd}, J=6.72 \mathrm{~Hz}, 3 \mathrm{H}), \delta 2.26-2.40$ $(\mathrm{dd}, J=6.1 \mathrm{~Hz}, 1 \mathrm{H}), \delta 4.08-4.22(\mathrm{~m}, 0.6 \mathrm{H}), \delta 4.32-4.42(\mathrm{~m}$, $0.4 \mathrm{H})$, and $\delta 4.43-4.56(\mathrm{~m}, 1 \mathrm{H})$.

4.3. Typical Procedure for the Michael Reaction and the Formation of Methyl 4-Nitropentanoate (6). The nitroalkane, nitroethane $(10 \mathrm{mmol})$, was mixed with the Michael acceptor, methyl acrylate $(10 \mathrm{mmol})$. After through mixing, the potassium carbonate catalyst $(30 \mathrm{~mol} \%)$ was added to the mixture. Heating or cooling was applied only when required, according to staring materials (Table 4). The reaction was left standing for the appropriate time. The catalyst was then filtered using a small column fitted with cotton and Florisil. The filtrate was then evaporated in vacuo and the crude product was purified via column chromatography using a mixture of cyclohexane and ethyl acetate affording the pure 6: IR (neat): $v_{\max } 3001,2956,2850,1732$, and $1556 \mathrm{~cm}^{-1} ;{ }^{1} \mathrm{H}$ NMR (250 MHz, CDCl $) \delta 4.74-4.59(\mathrm{~m}, 1 \mathrm{H}), \delta 3.70(\mathrm{~s}, 3 \mathrm{H})$, $\delta 2.45-2.01(\mathrm{~m}, 4 \mathrm{H})$, and $\delta 1.59-1.54(\mathrm{~d}, 3 \mathrm{H}, J=6.72 \mathrm{~Hz}) ;{ }^{13} \mathrm{C}$ NMR $\left(62.9 \mathrm{MHz}, \mathrm{CDCl}_{3}\right) \delta 172.4,82.4,51.9,30.0,29.9$, and 19.3.

\section{Conflicts of Interest}

The authors declare that there are no conflicts of interest regarding the publication of this paper.

\section{Acknowledgments}

The authors thank the University of Malta and the Strategic Educational Pathways Scholarship, Malta (European Social Fund (ESF) under Operational Programme II, Cohesion Policy 2007-2013, "Empowering People for More Jobs and a Better Quality Of Life”), for financial support.

\section{References}

[1] N. Ono, The Nitro Group in Organic Synthesis, John Wiley \& Sons, Inc., New York, NY, USA, 2001.

[2] G. Rosini, "Comprehensive Organic Synthesis," B. M. Trost, Ed., vol. 2, pp. 321-340, Pergamon, Oxford, UK, 1991.

[3] "Related Pergamon Titles of Interest," in Conjugate Addition Reactions in Organic Synthesis, vol. 9 of Tetrahedron Organic Chemistry Series, p. ii, Pergamon Press, Oxford, UK, 1992.

[4] R. Ballini and A. Palmieri, "Synthetic applications of nitroalkanes promoted by solid catalysis: recent results," Current Organic Chemistry, vol. 10, no. 17, pp. 2145-2169, 2006.

[5] F. A. Luzzio, “The Henry reaction: Recent examples," Tetrahedron, vol. 57, no. 6, pp. 915-945, 2001.

[6] R. Ballini, G. Bosica, D. Fiorini, A. Palmieri, and M. Petrini, "Conjugate additions of nitroalkanes to electron-poor alkenes: Recent results," Chemical Reviews, vol. 105, no. 3, pp. 933-971, 2005.

[7] K. Akutu, H. Kabashima, T. Seki, and H. Hattori, "Nitroaldol reaction over solid base catalysts," Applied Catalysis A: General, vol. 247, no. 1, pp. 65-74, 2003.

[8] A. Kumar and S. S. Pawar, "Catalyzing Henry reactions in chloroaluminate ionic liquids," Journal of Molecular Catalysis A: Chemical, vol. 235, no. 1-2, pp. 244-248, 2005.

[9] T. Angelini, E. Ballerini, S. Bonollo, M. Curini, and D. Lanari, "A new sustainable protocol for the synthesis of nitroaldol derivatives via Henry reaction under solvent-free conditions," Green Chemistry Letters and Reviews, vol. 7, no. 1, pp. 11-17, 2014.

[10] P. S. Shinde, S. S. Shinde, S. A. Dake et al., "CsF/[bmim][BF4]: An efficient and reusable system for Henry reaction," Arabian Journal of Chemistry, vol. 7, no. 6, pp. 1013-1016, 2014.

[11] G. Bosica and J. Gabarretta, "Unprecedented one-pot multicomponent synthesis of propargylamines using Amberlyst A-21 supported CuI under solvent-free conditions," RSC Advances, vol. 5, no. 57, pp. 46074-46087, 2015. 
[12] G. Bosica and R. Abdilla, "Aza-Michael mono-addition using acidic alumina under solventless conditions," Molecules, vol. 21, no. 6 , article no. 815, 2016.

[13] G. Bosica and R. Abdilla, "The $\mathrm{KA}^{2}$ coupling reaction under green, solventless, heterogeneous catalysis," Journal of Molecular Catalysis A: Chemical, vol. 426, pp. 542-549, 2017.

[14] M. B. Gawande, V. D. B. Bonifácio, R. Luque, P. S. Branco, and R. S. Varma, "Solvent-free and catalysts-free chemistry: A benign pathway to sustainability," ChemSusChem, vol. 7, no. 1, pp. 2444, 2014.

[15] R. Ballini, G. Bosica, D. Livi, A. Palmieri, R. Maggi, and G. Sartori, "Use of heterogeneous catalyst KG-60-NEt2 in Michael and Henry reactions involving nitroalkanes," Tetrahedron Letters, vol. 44, no. 11, pp. 2271-2273, 2003.

[16] B. M. Choudary, K. V. S. Ranganath, U. Pal, M. L. Kantam, and B. Sreedhar, "Nanocrystalline $\mathrm{MgO}$ for asymmetric Henry and Michael reactions," Journal of the American Chemical Society, vol. 127, no. 38, pp. 13167-13171, 2005.

[17] R. Ballini, G. Bosica, A. Palmieri, F. Pizzo, and L. Vaccaro, "Isolute ${ }^{5} \mathrm{Si}$-carbonate catalyzes the nitronate addition to both aldehydes and electron-poor alkenes under solvent-free conditions," Green Chemistry, vol. 10, no. 5, pp. 541-544, 2008.

[18] D. S. Khachatryan and K. R. Matevosyan, "Potassium carbonate as a base for generation of carbanions from $\mathrm{CH}$-acids in organic synthesis," Russian Chemical Bulletin, vol. 65, no. 1, pp. 14-28, 2016.

[19] R. Mondal and A. K. Mallik, "Recent applications of potassium carbonate in organic synthesis," Organic Preparations and Procedures International, vol. 46, no. 5, pp. 391-434, 2014.

[20] M. Ángeles López-García, I. Maya, J. G. Fernández-Bolaños, G. Bosica, and R. Ballini, "1-Alkoxyamino-2-nitroalkanes as key building blocks for a chemo- and diastereoselective synthesis of a new type of polyfunctionalized N-Alkoxypiperidine," European Journal of Organic Chemistry, no. 28, pp. 5482-5488, 2010.

[21] X. Lv, Y. Zhang, L. Zhou, and X. Wang, "Facile and efficient conjugate additions of $\beta$-dicarbonyl compounds and nitroalkanes to 4-aryl-4-oxobut-2-enoates," Journal of the Serbian Chemical Society, vol. 76, no. 7, pp. 947-954, 2011.

[22] S. G. Zlotin, A. V. Bogolyubov, G. V. Kryshtal, G. M. Zhdankina, M. I. Struchkova, and V. A. Tartakovsky, "Solvent-free synthesis of $\gamma$-nitroketones and $\gamma$-nitroesters promoted by the ionic liquid/K2CO3 catalytic system," Synthesis, no. 22, pp. 38493854, 2006.

[23] S.-X. Liu, C.-M. Jia, B.-Y. Yao, X.-L. Chen, and Q. Zhang, "Cascade Oxa-Michael-Henry Reaction of Salicylaldehydes with Nitrostyrenes via Ball Milling: A Solvent-Free Synthesis of 3-Nitro-2 H -chromenes," Synthesis (Germany), vol. 48, no. 3, Article ID ss-2015-h0497-op, pp. 407-412, 2016.

[24] R. Ballini, G. Bosica, A. Palmieri, and K. Bakhtiari, "Solventfree, anti-Michael addition of active methylene derivatives to $\beta$-nitroacrylates: Eco-friendly, chemoselective synthesis of polyfunctionalized nitroalkanes," Synlett, no. 2, pp. 268-270, 2009.

[25] Y.-M. Ren and C. Cai, "The Michael addition of active methylene compounds to chalcone derivatives using a catalytic amount of iodine and $\mathrm{K}_{2} \mathrm{CO}_{3}$ at room temperature," Journal of Chemical Research, vol. 35, no. 3, pp. 176-178, 2011.

[26] F. Scorzelli, A. Di Mola, L. Palombi, R. Filosa, and A. Massa, “3Carboxylate-Substituted Isoindolinones in K2CO3-Catalyzed Michael Reactions, Synthetic communications," Synthetic Communications, vol. 45, no. 13, pp. 1552-1558, 2015. 

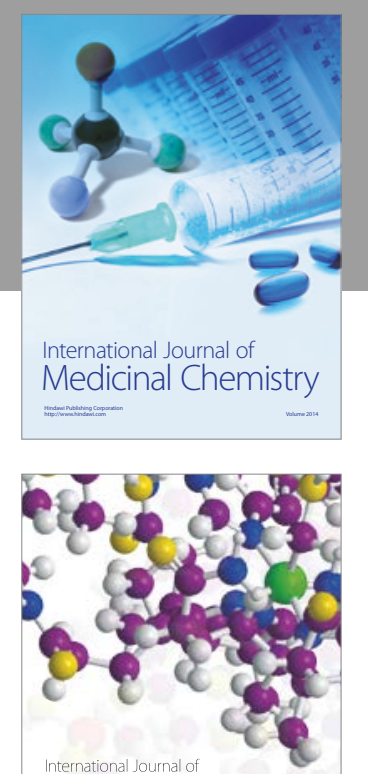

Carbohydrate Chemistry

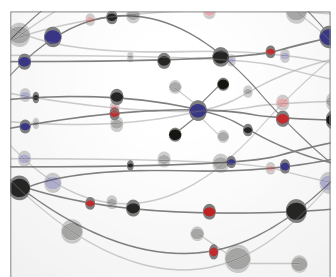

The Scientific World Journal
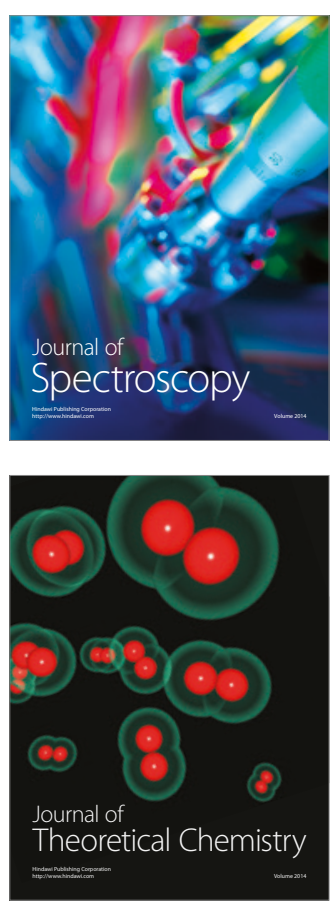
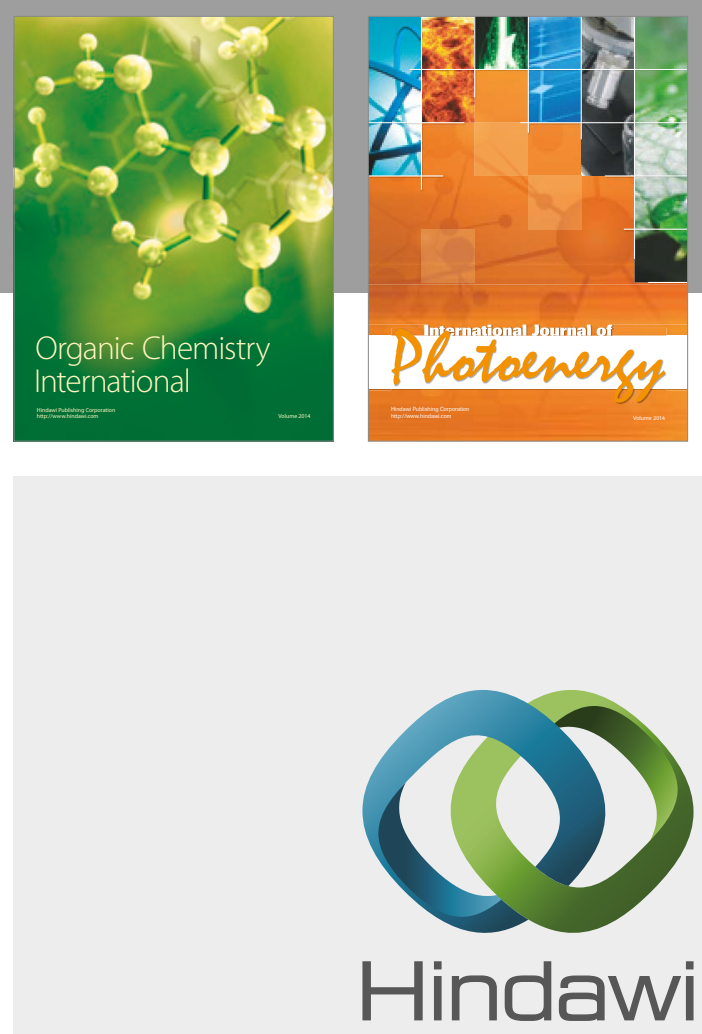

Submit your manuscripts at

https://www.hindawi.com

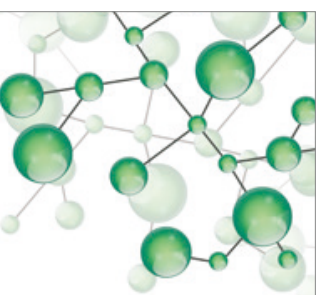

International Journal of

Inorganic Chemistry

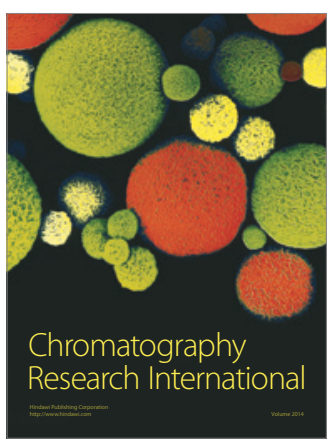

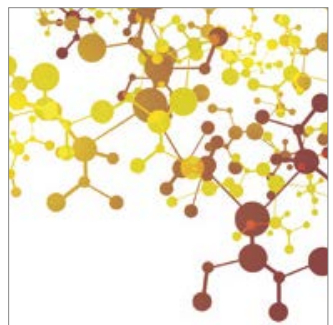

Applied Chemistry
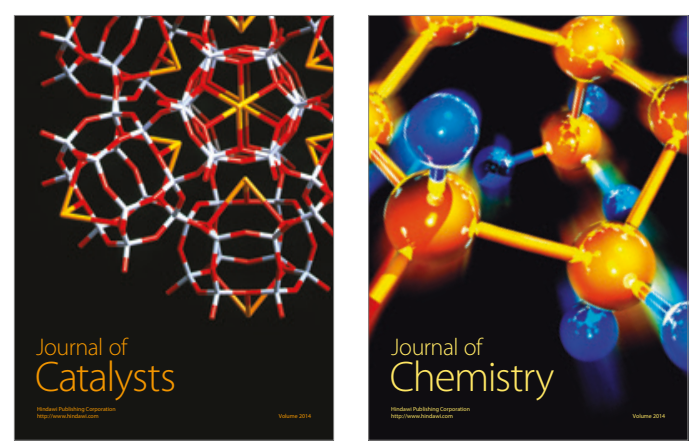
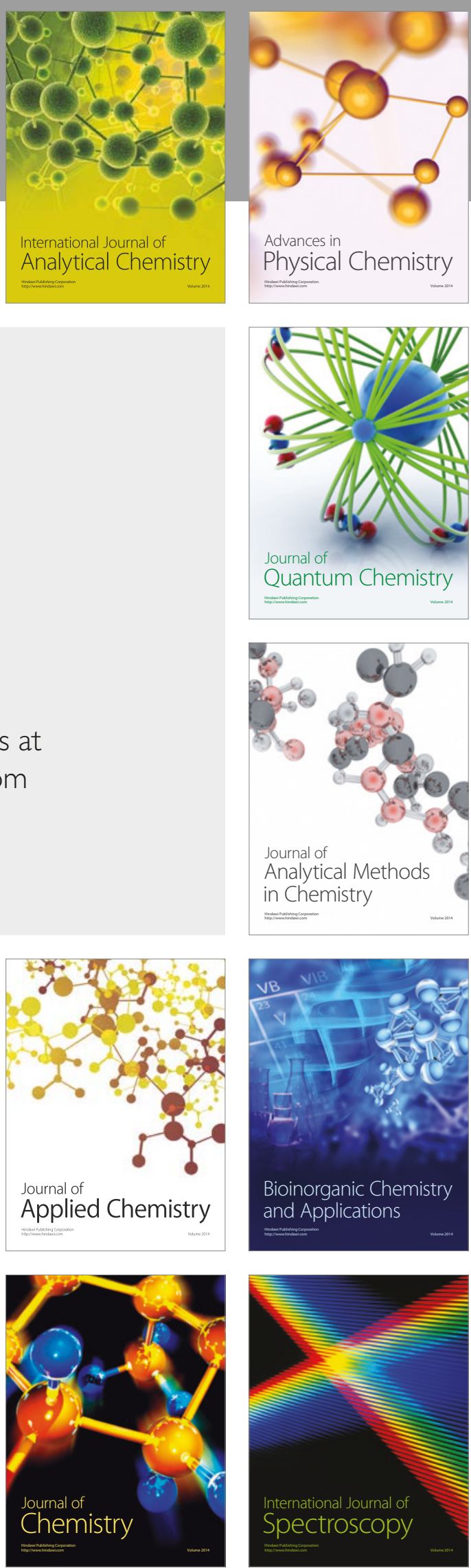